\title{
An overview on pedestrians involved in traffic accidents in Latvia: Years 2010-2014
}

\author{
A. Bukova-Zideluna ${ }^{1}$, A. Villerusa ${ }^{1}$, and A. Lama ${ }^{2}$ \\ ${ }^{1}$ Rīga Stradinš̌ University, Riga, Latvia \\ ${ }^{2}$ Road Traffic Safety Directorate, Riga, Latvia
}

\begin{abstract}
Latvian national road accident statistics shows that for the vulnerable road users' situation is critical, since pedestrians are involved in more than a quarter of road traffic accidents. This paper gives an analysis on pedestrians involved in road traffic accidents based on the road safety accident database in Latvia for the years 2010-2014. The total number of cases does not change significantly, however there has been an increase in pedestrian fatality rates over the period. From the total number of traffic accidents with pedestrians involved $92.4 \%$ had injuries, $6.8 \%$ were lethal cases and others did not suffer from injuries. Out of 342 fatalities $37.7 \%$ occurred during the winter period, $56.1 \%$ in adverse weather (overcast, fog, rain or snow), $69.9 \%$ during twilight or darkness and $26.9 \%$ on weekends. Out of all accidents $55.3 \%$ occurred in the capital city Riga, but fatality rate was higher on main state roads. $8.1 \%$ of the total number of pedestrians involved in road traffic accidents was found to have alcohol in their blood right after the road traffic accident. Fatality rate was higher for those with exceeded BAC. Pedestrian injury risk analysis was associated with demographical and traffic-related factors, urbanization, visibility and seasonal patterns.
\end{abstract}

\section{Introduction}

The issue of pedestrian safety has received an increasing attention from the researchers and transport planners. Every year the lives of approximately 1.25 million people are cut short as a result of a road traffic crash. $22 \%$ of those dying on the world's roads are pedestrians [1]. These accidents consume medical resources in the emergency, hospital and rehabilitation care, the patients and their families bear a heavy physical, emotional, and financial toll.

Road infrastructure is mainly constructed with the needs of motorists in mind, although almost half of all road traffic deaths occur among the vulnerable road users, which includes pedestrians as well. In the European Union the overall long-term tendency is for pedestrian fatalities to decrease slower than other fatalities since year 2010. The number of pedestrians killed on roads in the European Union has decreased by only $11 \%$, compared to the total fatality decrease of $18 \%$ in the period from 2010 to 2013 [2].

In 2016 European Transport Safety Council reported on Latvia having one of the highest risk numbers per head being killed as road users with more than 90 deaths per million inhabitants [3]. Data shows that $39 \%$ of all killed in road traffic crashes in Latvia 
are pedestrians, and the vulnerable road users are one of the top priorities defined in the national road safety program. The road safety plan proposes improvement in law and regulations, improved road user behaviour control and improved road users' awareness [4].

The objective of this research is to analyse road traffic accidents with pedestrians involved and the relations between injuries and the circumstances they occur in: the severity and types of injuries; and such causes as demographic characteristics and crash circumstances, including weather conditions and road typology.

\section{Methods}

This study gives analysis on road traffic accidents with pedestrians involved. In the current study the statistical database of road safety accidents and consequences in Latvia for the years 2010 to 2014, held by Road Traffic Safety Directorate, under the Ministry of Transport of Latvia, was used. The information held on the database covers close to $100 \%$ of all cases reported to the traffic police. Data is being collected from administrative protocols, which includes the protocols of road traffic accidents and fine slips from road police, and protocols and reports from other institutions of road traffic offences (for example, information on road traffic accidents without casualties is obtained from vehicle insurance companies).

Data-gathering protocol followed each case and then on-site investigation was carried out in order to identify pre-crash phenomena, such as road layout, light and weather conditions.

According to Road Traffic Safety Directorate a "death" is considered in those cases, where the victim has died on the accident site or within 30 days after. "Severe injuries" are those where the victims are hospitalized for more than one day, "minor injuries" - those hospitalized for up to 24 hours.

Regarding all pedestrians involved in road traffic accidents, the following information was gathered and analysed:

1. pedestrian-related variables: age (younger than $35,35-54,55$ and older) and sex;

2. severity of injuries (no injuries, severe, minor injuries or death);

3. environmental variables: zone (open road, urban), time (daylight, twilight, darkness), type of day (working day or weekend), month of the year, surface and overcast weather conditions;

4. BAC (blood alcohol concentration) prior to the accident.

Data was downloaded, processed and analysed using descriptive statistics, Pearson's chisquared and calculations of statistical reliability with SPSS for Windows 20.0. The 95\% confidence interval (CI) was used to estimate the precision of the odds ratio (OR).

\section{Results}

From the 2010 to 2014,5030 pedestrians were involved in reported road traffic accidents in Latvia. Fatal accident risk for pedestrians involved in traffic accidents has increased compared to all accidents with pedestrians. The annual rate of pedestrians involved in road traffic accidents is displayed in Table 1 . 
Table 1. The annual number of pedestrians based on severity and proportion.

\begin{tabular}{|c|c|c|c|c|c|}
\hline Year & $\begin{array}{c}\text { No } \\
\text { injuries }\end{array}$ & $\begin{array}{c}\text { Minor } \\
\text { injuries }\end{array}$ & $\begin{array}{c}\text { Serious } \\
\text { injuries }\end{array}$ & Fatalities & $\begin{array}{c}\text { Total number (\% } \\
\text { of cases in period) }\end{array}$ \\
\hline 2010 & $10(1.0 \%)$ & $786(77.1 \%)$ & $145(14.2 \%)$ & $79(7.7 \% 0$ & $1020(20.3 \%)$ \\
\hline 2011 & $6(0.6 \%)$ & $805(80.3 \%)$ & $131(13.1 \%)$ & $60(6.0 \%)$ & $1002(19.9 \%)$ \\
\hline 2012 & $8(0.8 \%)$ & $807(81.6 \%)$ & $111(11.2 \%)$ & $62(6.3 \%)$ & $988(19.6 \%)$ \\
\hline 2013 & $9(0.9 \%)$ & $811(91.1 \%)$ & $110(11.0 \%)$ & $70(7.0 \%)$ & $1000(19.9 \%)$ \\
\hline 2014 & $6(0.6 \%)$ & $847(83.0 \%)$ & $96(9.4 \%)$ & $71(7.0 \%)$ & $1020(20.3 \%)$ \\
\hline
\end{tabular}

\subsection{Pedestrian characteristics}

There were 2157 male (42.9\%) and 1758 female (35.0\%) pedestrians; but in $22.2 \%$ of cases sex was not recorded in the police protocol. Most pedestrians (46.5\%) were under 35, but rate of serious injuries was higher for the 35-54 year old group. Fatality rate was higher for those 55 years and older. The characteristics of pedestrians involved in road traffic accidents according to the age are displayed in Table 2 .

Table 2. The number of accidents and severity of injuries based on age.

\begin{tabular}{|c|c|c|c|c|c|}
\hline Age & $\begin{array}{c}\text { No } \\
\text { injuries }\end{array}$ & $\begin{array}{c}\text { Minor } \\
\text { injuries }\end{array}$ & $\begin{array}{c}\text { Serious } \\
\text { injuries }\end{array}$ & Fatalities & $\begin{array}{c}\text { Total number (\%) } \\
\text { of cases in } \\
\text { period) }\end{array}$ \\
\hline $\begin{array}{c}\text { Younger } \\
\text { than 35 }\end{array}$ & $\begin{array}{c}28 \\
(1.2 \%)\end{array}$ & $\begin{array}{c}2007 \\
(85.8 \%)\end{array}$ & $\begin{array}{c}236 \\
(10.1 \%)\end{array}$ & $68(2.9 \%)$ & $2339(46.5 \%)$ \\
\hline $35-54$ & $6(0.5 \%)$ & $891(76.7 \%)$ & $\begin{array}{c}158 \\
(13.6 \%)\end{array}$ & $107(9.2 \%)$ & $1162(23.1 \%)$ \\
\hline 55 and older & $5(0.3 \%)$ & $\begin{array}{c}1158 \\
(75.7 \%)\end{array}$ & $\begin{array}{c}199 \\
(13.0 \%)\end{array}$ & $\begin{array}{c}167 \\
(10.9 \%)\end{array}$ & $1529(30.4 \%)$ \\
\hline $\begin{array}{c}\text { Total number } \\
(\%) \text { of injury } \\
\text { by severity } \\
\text { in all ages }\end{array}$ & $\begin{array}{c}39 \\
(0.8 \%)\end{array}$ & $\begin{array}{c}4056 \\
(80.6 \%)\end{array}$ & $\begin{array}{c}593 \\
(11.8 \%)\end{array}$ & $342(6.8 \%)$ & $5030(100 \%)$ \\
\hline
\end{tabular}

Differences between sex and injury/fatality rate (Pearson's chi-squared test $\chi^{2}=80.334$; p-value $<0.0001)$ are statistically significant. Differences between age groups and injury/fatality rate (Pearson's chi-squared test $\chi^{2}=136.54$; p-value $<0.0001$ ) are statistically significant.

\subsection{Characteristics of accident conditions}

A total of $40.4 \%$ of pedestrians were involved in road traffic accidents during twilight or dark, and $42.6 \%$ of accidents occurred during overcast, fog and rain or snow. The light and weather conditions are shown in Table 3.

Police protocols gave incomplete reports on accident conditions, which mean there was some missing data on the light and weather conditions in total numbers. The differences between light condition and injury/fatality rate (Pearson's chi-squared test $\chi^{2}=163.384$; $\mathrm{p}$ value $<0.0001)$ are statistically significant, fatality rate is higher for twilight and dark conditions (odd ratio OR $=3.750$; confidence interval CI 2.953-4.761). Differences between weather condition and injury/fatality rate (Pearson's chi-squared test $\chi^{2}=22.717$; 
p-value $<0.0001)$ are statistically significant, fatality rate is higher for adverse weather (OR $=1.792$; CI 1.436-2.236).

Table 3. Characteristics of pedestrians involved in accidents based on the light and weather conditions.

\begin{tabular}{|c|c|c|c|c|}
\hline \multicolumn{2}{|r|}{ Conditions } & $\begin{array}{c}\text { No injuries, } \\
\text { minor or serious } \\
\text { injuries }\end{array}$ & Fatality & $\begin{array}{l}\text { Total number } \\
(\%) \text { of all cases } \\
\text { by accident } \\
\text { condition } \\
\end{array}$ \\
\hline \multirow{3}{*}{$\begin{array}{l}\text { Light } \\
\text { condition }\end{array}$} & Daylight & $2796(96.4 \%)$ & $103(3.6 \%)$ & $2899(59.6 \%)$ \\
\hline & Twilight, dark & $1730(87.9 \%)$ & $239(12.1 \%)$ & $1969(40.4 \%)$ \\
\hline & $\begin{array}{l}\text { Total number }(\%) \text { of } \\
\text { injury by severity }\end{array}$ & $4526(93.0 \%)$ & $342(7.0 \%)$ & $4868(100 \%)$ \\
\hline \multirow{3}{*}{$\begin{array}{l}\text { Weather } \\
\text { condition }\end{array}$} & Not adverse weather & $2735(94.8 \%)$ & $150(5.2 \%)$ & $2885(57.4 \%)$ \\
\hline & $\begin{array}{c}\text { Adverse weather } \\
\text { (overcast, fog, rain or } \\
\text { snow) }\end{array}$ & $1953(91.1 \%)$ & $192(9.0 \%)$ & $2145(42.6 \%)$ \\
\hline & $\begin{array}{l}\text { Total number }(\%) \text { of } \\
\text { injury by severity }\end{array}$ & $4688(93.2 \%)$ & $342(6.8 \%)$ & $5030(100 \%)$ \\
\hline
\end{tabular}

\subsection{Seasonal and weekday characteristics}

Looking at the time of a year, more pedestrians suffered in accidents during autumn (September, October, and November) and winter (December, January, and February). Comparing the severity of injuries across the seasons, data shows that fatality percentage was higher in autumn, but serious injury percentage was higher in winter and spring. The correlation between the season and injury/fatality rate is statistically significant (Pearson's chi-squared test $\chi^{2}=31.899$; p-value $<0.0001$ ).

There were four times more pedestrians involved in traffic accidents on weekdays than on weekends, but rates for fatality and serious injuries were higher on weekends than on weekdays. The analysis of injuries on weekdays compared to weekends shows statistically significant differences (Pearson's chi-squared test $\chi^{2}=21.591 ; \mathrm{p}$-value $<0.0001$ ). Fatality rate is higher for weekends $(\mathrm{OR}=1.467$; CI 1.143-1.883). Characteristics of pedestrians involved in road traffic accidents according to the seasons and the day of week are shown in Table 4.

Table 4. Characteristics of pedestrians involved in accidents and severity of injuries based on the seasons and the day of week.

\begin{tabular}{|l|l|l|l|l|l|}
\hline $\begin{array}{l}\text { Season/ } \\
\text { weekday }\end{array}$ & No injuries & $\begin{array}{l}\text { Minor } \\
\text { injuries }\end{array}$ & $\begin{array}{l}\text { Serious } \\
\text { injuries }\end{array}$ & Fatality & $\begin{array}{l}\text { Total } \\
\text { number (\%) } \\
\text { of all cases }\end{array}$ \\
\hline Winter & $7(0.5 \%)$ & $1090(79.8 \%)$ & $171(12.5 \%)$ & $98(7.2 \%)$ & $1366(27.2 \%)$ \\
\hline Spring & $10(0.9 \%)$ & $864(80.4 \%)$ & $135(12.6 \%)$ & $66(6.1 \%)$ & $1075(21.4 \%)$ \\
\hline Summer & $14(1.2 \%)$ & $962(84.0 \%)$ & $120(10.5 \%)$ & $49(4.3 \%)$ & $1145(22.8 \%)$ \\
\hline Autumn & $8(0.6 \%)$ & $1140(78.9 \%)$ & $167(11.6 \%)$ & $129(8.9 \%)$ & $1444(27.7 \%)$ \\
\hline Weekdays & $29(0.7 \%)$ & $3276(81.9 \%)$ & $443(11.1 \%)$ & $250(6.3 \%)$ & $3998(79.5 \%)$ \\
\hline Weekend & $10(1.0 \%)$ & $780(75.6 \%)$ & $150(14.5 \%)$ & $92(8.9 \%)$ & $1032(20.5 \%)$ \\
\hline Total & $39(0.8 \%)$ & $4056(80.6 \%)$ & $593(11.8 \%)$ & $342(6.8 \%)$ & $5030(100 \%)$ \\
\hline
\end{tabular}




\subsection{Characteristics of pedestrians involved in road accidents based on the time of accident}

During the day time there have been mostly minor injuries (12:00-15:59), while serious injuries and fatalities occurred more during the night time (00:00-03:59). In total number of all cases more pedestrians suffered in traffic accidents in late afternoon (16:00-19:59). Table 5 presents the overall percentages of pedestrians injured according to the time of accident.

Table 5. Characteristics of injured pedestrians based on the time of accident.

\begin{tabular}{|c|c|c|c|c|c|}
\hline Time & $\begin{array}{c}\text { No } \\
\text { injuries }\end{array}$ & $\begin{array}{c}\text { Minor } \\
\text { injuries }\end{array}$ & $\begin{array}{c}\text { Serious } \\
\text { injuries }\end{array}$ & Fatality & $\begin{array}{c}\text { Total number (\%) } \\
\text { of all cases by time }\end{array}$ \\
\hline $00: 00-03: 59$ & $1(0.6 \%)$ & $126(70.8 \%)$ & $27(15.2 \%)$ & $24(13.5 \%)$ & $178(4.6 \%)$ \\
\hline $04: 00-07: 59$ & 0 & $187(79.6 \%)$ & $27(11.5 \%)$ & $21(8.9 \%)$ & $235(6.1 \%)$ \\
\hline $08: 00-11: 59$ & $4(0.6 \%)$ & $518(83.5 \%)$ & $72(11.6 \%)$ & $26(4.2 \%)$ & $620(16.2 \%)$ \\
\hline $12: 00-15: 59$ & $\begin{array}{c}11 \\
(1.3 \%)\end{array}$ & $704(85.4 \%)$ & $75(9.1 \%)$ & $34(4.1 \%)$ & $824(21.5 \%)$ \\
\hline $16: 00-19: 59$ & $8(0.6 \%)$ & $1038(79.9 \%)$ & $\begin{array}{c}147 \\
(11.0 \%)\end{array}$ & $113(8.5 \%)$ & $1336(34.8 \%)$ \\
\hline $20: 00-23: 59$ & $2(0.3 \%)$ & $475(73.6 \%)$ & $98(15.2 \%)$ & $70(10.9 \%)$ & $645(16.8 \%)$ \\
\hline
\end{tabular}

\subsection{Characteristics of pedestrians injured based on the place of accident}

$55.3 \%$ of pedestrian road accidents occurred in the capital city, Riga, 30.8\% happened in other big cities and $14.8 \%$ on the main roads, regional and local roads. $28.6 \%$ of the serious injuries occurred on local roads, and $28.2 \%$ of fatalities occurred on main state roads. Differences between the accident place and injury/fatality rate are what statistically significant (Pearson's chi-squared test $\chi^{2}=631.210$; $p$-value $<0.0001$ ). Table 6 presents characteristics of pedestrians according to the place of accident.

Table 6. Characteristics of pedestrians based on the place of accident.

\begin{tabular}{|c|c|c|c|c|c|}
\hline Place & $\begin{array}{c}\text { No } \\
\text { injuries }\end{array}$ & $\begin{array}{c}\text { Minor } \\
\text { injuries }\end{array}$ & $\begin{array}{c}\text { Serious } \\
\text { injuries }\end{array}$ & Fatality & $\begin{array}{c}\text { Total number (\%) } \\
\text { of all cases by place }\end{array}$ \\
\hline $\begin{array}{c}\text { Main state } \\
\text { roads }\end{array}$ & $2(0.5 \%)$ & $221(52.7 \%)$ & $78(18.6 \%)$ & $\begin{array}{c}118 \\
(28.2 \%)\end{array}$ & $419(9.4 \%)$ \\
\hline $\begin{array}{c}\text { Regional } \\
\text { roads }\end{array}$ & 0 & $91(46.4 \%)$ & $53(27.0 \%)$ & $52(26.5 \%)$ & $196(3.9 \%)$ \\
\hline $\begin{array}{c}\text { Local } \\
\text { roads }\end{array}$ & 0 & $49(63.6 \%)$ & $22(28.6 \%)$ & $6(7.8 \%)$ & $77(1.5 \%)$ \\
\hline $\begin{array}{c}\text { Capital } \\
\text { city - Riga }\end{array}$ & $24(0.9 \%)$ & $2392(86.7 \%)$ & $254(9.2 \%)$ & $88(3.2 \%)$ & $2758(55.3 \%)$ \\
\hline Other city & $13(0.8 \%)$ & $1263(82.2 \%)$ & $\begin{array}{c}185 \\
(12.0 \%)\end{array}$ & $75(4.9 \%)$ & $1536(30.8 \%)$ \\
\hline
\end{tabular}

\subsection{Blood alcohol concentration}

During the five years of under study, 407 (8.1\%) pedestrians were found to have alcohol in their blood right after the road traffic accident. Fatality rate is higher for those with exceeded BAC $(\mathrm{OR}=1.167$; CI 0.794-1.714). Table 7 shows overall tendencies in correlation between the pedestrians involved in traffic accidents and BAC. 
Table 7. Blood alcohol concentration among pedestrians involved in traffic accidents.

\begin{tabular}{|c|c|c|c|c|c|}
\hline $\begin{array}{c}\text { Alcohol } \\
\text { presence }\end{array}$ & $\begin{array}{c}\text { No } \\
\text { injuries }\end{array}$ & $\begin{array}{c}\text { Minor } \\
\text { injuries }\end{array}$ & $\begin{array}{c}\text { Serious } \\
\text { injuries }\end{array}$ & Fatality & $\begin{array}{c}\text { Total number (\%) } \\
\text { of all cases by } \\
\text { BAC }\end{array}$ \\
\hline No alcohol & $38(0.8 \%)$ & $3740(80.9 \%)$ & $\begin{array}{c}540 \\
(11.7 \%)\end{array}$ & $305(6.6 \%)$ & $4623(91.9 \%)$ \\
\hline $\begin{array}{c}\text { Positive } \\
\text { BAC }\end{array}$ & $1(0.2 \%)$ & $316(77.6 \%)$ & $53(13.0 \%)$ & $31(9.7 \%)$ & $407(8.1 \%)$ \\
\hline
\end{tabular}

\section{Discussion}

Through the analysis of traffic police data, this study systematically examined the causes of injuries among pedestrians involved in traffic accidents in Latvia. In the period from 2010 to 2014,5030 pedestrians were involved in road traffic accidents. The total number of cases does not change significantly, however there has been an increase in pedestrian fatality rate over the period.

Both - injuries and fatalities - in pedestrian accidents were correlated to male gender. In comparison a larger percentage of female than male pedestrian deaths occur in other European Union countries [5], while Abay showed that one of the factors that increased the risk of a fatal injury for pedestrians was the male gender [6]. Elderly pedestrians are particularly at risk - the proportion of pedestrian fatalities increases for the age group of 35-44 as compared to those under 35, and this increases even more for the group aged above 55, which is relevant to other findings. European Commission showed that around $44 \%$ of all killed pedestrians were 65 years old or older [2]. The increased fatality rate can be explained by physical vulnerability as older people are less able to endure injuries.

The role of light circumstances is important since results of the study show that twilight and darkness are related to a high proportion of fatal pedestrian accidents. This study shows that adverse weather conditions (overcast, fog, rain or snow) are related to pedestrian fatalities. Most fatalities occurred during the autumn, the percentage of serious injuries was higher in winter and spring suggesting that the greatest proportion of pedestrian traffic accidents happened due to bad visibility. The analysis showed that injuries mostly occurred in a late afternoon, suggesting that the greatest proportion of traffic accidents were related to traffic after working hours. However, the biggest part of serious injuries and fatalities occurred at late evening or night time. This indicates that a high proportion of fatal traffic accidents are related to visibility. These results are in line with the findings of other research studies on the fundamental limitations of vision [7, 8]. In these cases, use of reflective materials on the pedestrian could likely reduce fatality risk while walking in dark conditions.

This study shows that pedestrians face a large risk on urban roads. However, the largest percentage of serious injuries occurred on local and regional roads, and the largest percentage of fatalities occurred on the main state roads. The traffic mix outside cities makes the pedestrians share the road with vehicles, forcing them into dangerous situations in fast-moving traffic.

The current study also shows the relation between fatalities and pedestrian intoxication, showing that drunk walking is related to injuries and fatalities in road traffic accidents. Öström showed positive blood alcohol in 19\% of the fatalities in Sweden [9], while in the United States nearly four out of ten pedestrians killed had had some level of alcohol involvement at the time of the crash [10]. Alcohol use among pedestrians has been a relatively neglected issue when compared with alcohol use among drivers. Educational programs can be designed to inform pedestrians about the dangers posed by alcohol consumption. 


\section{Conclusions}

Pedestrian injuries and death are related to preventable risk factors. In this study pedestrian fatalities are analysed based on demographical factors (males, older adults), blood alcohol concentration and accident circumstances (adverse weather, dark light conditions, night time, main state roads and weekends).

Making walking safer is critical for reducing the number of road traffic deaths. A key strategy for achieving a safe traffic system for pedestrians is to separate different kinds of road use, eliminating conflicts between high-speed vehicles and vulnerable road users. It is clear that both environmental and behavioural measures aimed at reducing collisions will be important in reducing the overall incidence of pedestrian injuries.

This study has some limitations. Protocols on accident conditions were reported incompletely, which means there was some missing data in the total numbers. The results of the analyses allow an overall assessment of pedestrian safety level in Latvia. Certainly, the effort of data collection is an on-going challenge and the analysis presented in this study in the future could be combined with more detailed analysis of additional data to emphasize the problem.

\section{References}

1. World Health Organization, Global status report on road safety, 2-8 (2015)

2. European Commission, Road safety in European Union: trends, statistics and main challenges 13 (2015)

3. European Transport Safety Council, Ranking EU progress on road safety: 10th Road Safety Performance Index Report 17 (2016)

4. Latvijas Republikas Ministru Kabinets, Ceļu satiksmes drošĭbas plāna 2014.2016.gadam kopsavilkum (2014)

5. $\quad$ European Transport Safety Council, Risk on the roads - A Male Problem 25 (2013)

6. K.A. Abay, Res in Transp Econ Examining pedestrian-injury severity using alternative disaggregate models 43, 123-136 (2013)

7. M. Sivak, J. Luoma, M.J. Flannagan et al., J Safety Res Traffic safety in the U.S.: Re-examining major opportunities 38, 337-355 (2007)

8. J.M. Sullivan, K.J. Flannagan, Accid Anal Prev The role of ambient light level in fatal crashes: inferences from daylight saving time transitions 34, 487-498 (2002)

9. M. Öström, A. Eriksson, Accid Anal Prev Pedestrian fatalities and alcohol 33, 173$180(2001)$

10. Department of Transportation, National Highway Traffic Safety Administration National Pedestrian Crash Report 26 (2008) 
